\title{
Interdisciplinary Computing
}

\author{
Applied Computing for Behavioral and Social Sciences
}

\author{
Valerie Carr \\ Dept. of Psychology \\ San Jóse State University \\ San Jose, CA, USA \\ valerie.carr@sjsu.edu
}

\author{
Morris Jones \\ Dept. of General Engineering \\ San Jóse State University \\ San Jose, CA, USA \\ morris.jones@sjsu.edu
}

\author{
Belle Wei \\ Dept. of General Engineering \\ San Jóse State University \\ San Jose, CA, USA \\ belle.wei@sjsu.edu
}

\begin{abstract}
As the digital economy grows, so does the demand for technology-capable workers who have both computing skills and domain expertise. Growing such a workforce is critical to ensuring the nation's competitiveness, according to a recent National Science Board publication. To address this need, faculty from the Colleges of Engineering and Social Sciences at San Jóse State University worked together to create the Applied Computing for Behavioral and Social Sciences minor degree. The minor targets students in majors such as Psychology and Economics, which have a more diverse student population than that of Computer Science or Engineering. The minor, designed with industry input, includes a four-course sequence that focuses on Python and $\mathrm{R}$ and includes topics such as data structures, algorithms, data cleaning and management, and data analysis. Our cohort-based program was built specifically for social science students using social science content, helping to foster a sense of community and belongingness among students. The first full cohort of 26 students graduated in Spring 2019, 48\% of whom were female and $23 \%$ of whom were underrepresented minorities. Our approach of embedding computing education into the social sciences demonstrates a promising model of broadening participation in computing and meeting the nation's increasing demand for interdisciplinary computing workers in the digital age.
\end{abstract}

\section{KEYWORDS}

Interdisciplinary Computing, Computing for Social Sciences, Data Science for Social Sciences, Applied Computing, Broadening Participation in Computing, New Degree Program

Permission to make digital or hard copies of all or part of this work for personal or classroom use is granted without fee provided that copies are not made or distributed for profit or commercial advantage and that copies bear this notice and the full citation on the first page. Copyrights for components of this work owned by others than ACM must be honored. Abstracting with credit is permitted. To copy otherwise, or republish, to post on servers or to redistribute to lists, requires prior specific permission and/or a fee. Request permissions from Permissions@acm.org.

SIGCSE '20, March 11-14, 2020, Portland, OR, USA

(C) 2020 Association for Computing Machinery.

ACM ISBN 978-1-4503-6793-6/20/03...\$15.00.

https://doi.org/10.1145/3328778.3366799

\section{ACM Reference format:}

Valerie Carr, Morris Jones and Belle Wei. 2020. Interdisciplinary Computing: Applied Computing for Behavioral and Social Sciences. In Proceedings of the $51^{\text {st }}$ ACM Technical Symposium on Computer Science Education (SIGCSE'20), March 11-14, 2020, Portland, OR, USA. ACM, New York, NY, USA, 7 pages. https://doi.org/10.1145/3328778.3366799

\section{INTRODUCTION}

The growing technology-based economy has increased the demand for technology professionals, as well as technologycapable workers who are needed to fill hybrid or interdisciplinary computing jobs. These jobs require workers to have technology-related skills such as programming and data sciences, as well as knowledge in other domains [2, 9, 12]. However, there is a significant gap between the supply and demand of technology-capable workers. The US Bureau of Labor Statistics projects 1.1 million job openings in computing and information technology by 2024, but only 450,000 Computer Science graduates to fill them $[13,18]$. This gap, if unmitigated, retards economic growth and exacerbates income inequality [5]. According to a recent National Science Board publication [12], the US can no longer rely on a relatively small traditional technology workforce. Instead, the US needs to grow a technology-capable workforce in order to ensure the nation's competitiveness.

To address these challenges, we have developed a new interdisciplinary computing minor degree at San Jóse State University (SJSU): Applied Computing for Behavioral and Social Sciences. In developing this program, we considered the following three factors. First, with the emergence of big data, modeling human behaviors and social interactions is a fruitful area in which our technology-capable graduates can pursue career opportunities and advanced studies. Second, a large number of diverse students are studying behavioral and social sciences, both at SJSU and across the US. Behavioral and social science majors accounted for $14 \%$ of bachelor's degrees awarded in the US in 2017 [11]; locally, they accounted for $18 \%$ of bachelor's degrees awarded in 2019 [16]. Within the College of Social Sciences, 59\% of students are female, and $44 \%$ of underrepresented (URM) students. In comparison, 19\% of College of Engineering students are female, and only $22 \%$ are URM students [16]. Third, social science majors have among the highest unemployment rates of all college graduates, but 
students who supplement their domain expertise with computing skills can double the number of available jobs and raise their salaries significantly [1]. Indeed, the average STEM wage in Silicon Valley is $\$ 104,110$, nearly twice that of nonSTEM wages of $\$ 52,740$ [15]. The goal of the Applied Computing program is to provide social science students with computing education that will expand their career opportunities and increase their income, in turn helping to address the national need for a technology-capable workforce.

In developing our minor degree program, we considered existing interdisciplinary computing degree programs, often designated as CS + X (e.g., University of Illinois, Stanford University) or Applied Computing (e.g., Arizona State University, University of Washington - Bothell). By and large, such programs cater to students interested in majoring in CS with a minor in $\mathrm{X}$, or double majoring in CS and X. In these programs, CS + X students typically enroll in existing CS courses alongside CS students. Given the non-technical background of social science students, we opted to take a different approach. We developed an entirely new series of courses with content crafted specifically for these students, such that classes are taken only with fellow social science students (similar to the computational social science minor at UC San Diego). Additionally, an interdisciplinary team of faculty from both the social science and computing fields collaboratively design and teach these courses.

Our successful implementation of the new minor has depended on (a) sufficient elective units in the target majors (e.g., Psychology and Economics) to enable students to pursue a minor without delaying their graduation, (b) an interdisciplinary team of faculty from both the Colleges of Engineering and Social Sciences who are committed to the program's success, (c) supportive administrators, i.e., chairs and deans, from both Colleges, and (d) resources to develop and launch the new degree program, including our NSF Improving Undergraduate STEM Education (IUSE) grant.

\section{DEGREE PROGRAM DEVELOPMENT}

Development of the Applied Computing program has included designing the curricula, building infrastructure for interdisciplinary collaboration, and creating industry partnerships (see Figure 1). NSF funding supported all phases of this process, by, e.g., providing summer pay for faculty to develop new courses and attend computing education conferences, and hosting a yearly meeting for faculty and industry partners.

\subsection{DEVELOPING CURRICULA}

The goal of the new Applied Computing minor is to provide computing education to social science majors for technologyrelated careers. An interdisciplinary team of faculty (see section 2.2) has worked together to develop and subsequently improve a series of four courses comprising the minor (see section 3). In brief, these courses cover an introduction to programming, data structures and algorithms, data technology, and a capstone project. In developing curricula for students with no

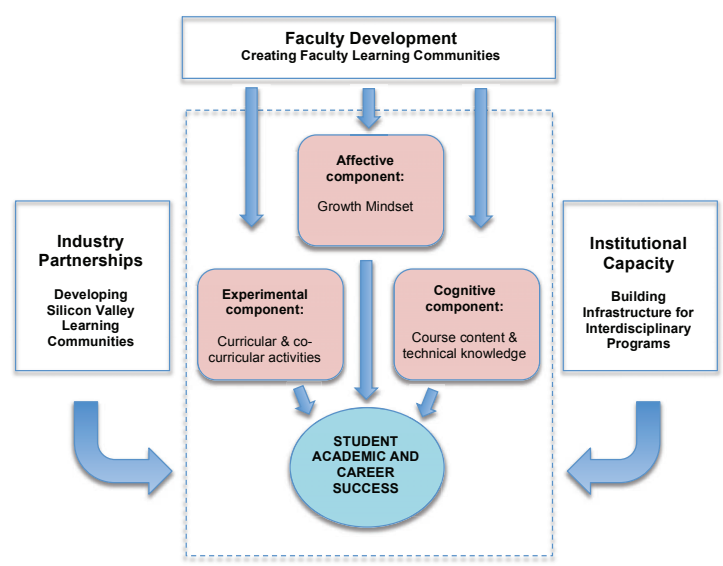

Figure 1: A System View of the Applied Computing for Behavioral and Social Sciences Minor

programming and very little math background, particular attention was paid to pedagogical approaches and high-impact practices that motivate and support student learning [7]. In particular, the program uses contextualized problem-based pedagogy in which students acquire relevant technical knowledge by solving real-world social science problems. The course sequence is carefully designed to scaffold student learning with the aid of a growth mindset [14] that encourages students to persist in their learning.

Furthermore, courses are designed to be taken serially, creating a cohort structure that helps provide students a sense of community and belongingness, thus enabling them to network and support one another throughout their academic careers. Students from all stages of the minor are also given the opportunity to interact with industry professionals and Applied Computing alumni through co-curricular activities such as guest lectures and mixers. The opportunity to network with industry professionals with similar backgrounds provides students relatable role models and inspirational examples.

\subsection{INFRASTRUCTURE}

To ensure the long-term success of a new interdisciplinary degree program, it is important to develop organizational infrastructures and extensive collaborations across disciplinary and organizational boundaries. We therefore created an interdisciplinary team of nine faculty from the Colleges of Social Sciences, Engineering, and Education. The faculty have a broad spectrum of experience including teaching, research, faculty development, administration, and industry. This breadth and depth of experience is critical to building capacity for intracampus collaboration, as well as creating a partnership between academia and industry. Since its initial formation, our faculty team has met every month to discuss programmatic and pedagogical issues. Additionally, our team has convened an annual Interdisciplinary Computing Summer Institute each year since 2017, which brings together our faculty, faculty from other campuses, and industry partners to determine how to best develop new interdisciplinary computing talent. 


\subsection{INDUSTRY PARTERNSHIPS}

Given our program's orientation towards career preparation, it is critical for us to develop strong industry partnerships. Our industry partners provide invaluable input regarding curricular design, such as how to foster both the technical and workplace skills necessary for an interdisciplinary computing career. Industry partners also give guest lectures in classes, participate in workshops and panels, recommend project ideas, advise students, and serve as key connections for obtaining internship and career opportunities.

\section{CURRICULA AND PEDAGOGY}

The Applied Computing minor consists of four, three-unit courses - a size selected so as not to delay time to graduation. Courses include:

1. ENGR 120: Programming Concepts for Behavioral and Social Science Applications (Python)

2. ENGR 121: Data Structures and Algorithms for Behavioral and Social Science Applications (Python)

3. ENGR 122: Data Technology for Behavioral and Social Science Applications (R)

4. ENGR 195E: Interdisciplinary Computing Project

The minor is designed to be completed serially, given that each course builds upon the last. Most students begin the minor during their junior year after completing a statistics course, a required prerequisite, and then take one course per semester until they graduate. It bears noting that a large number of students have taken the first course in the series, ENGR 120, without enrolling in subsequent courses, as reflected in Table 1. This trend is partially due to the fact that students enrolled in initial course offerings graduated before all minor courses were available. Additionally, via a survey routinely administered at the end of ENGR 120, those students who indicated that they did not intend to complete the minor reported insufficient time to complete all four courses prior to graduating. As a result, we now specifically target incoming transfer students to ensure that they are aware of the minor and have sufficient time to complete all necessary courses.

ENGR 120. Given that ENGR 120 requires no prior programming experience, instructors gradually introduce basic Python programming concepts (data types, conditional execution, iteration, functions, data analysis, web scraping) through a social science lens while using evidence-based practices and fostering a growth mindset. The course is taught in a hybrid lecture-lab format to encourage active learning of concepts and skills that are radically different from that of students' major courses. This approach is supported by psychological research indicating that information is better retained when it is generated by learners themselves [17]. Students are also required to turn in weekly homework assignments, allowing for repeated practice and regular feedback, both of which are key to successfully encoding new skills [4]. Critically, research shows that being tested is in and of itself critical to successful learning [6], to which end students take regular quizzes throughout the semester rather than a midterm and final exam. Each lecture also includes a "Spotlight" segment designed to introduce students to industry terminology and interdisciplinary computing career paths.

ENGR 121. The second course in the series, Data Structures and Algorithms (Python), teaches students to represent and analyze social science data, to use data structures such as linked lists, trees, and graphs, and to use related algorithms to solve social science problems. For example, students use data from the Bureau of Labor Statistics to identify and compare popular industries in different states, and they scrape content from social media sites and then apply natural language processing and sentiment analysis. Instructors in this and all subsequent courses continue to engage in the pedagogical approaches listed above, encouraging a growth mindset to help students persist in their learning, particularly in this more technical course.

ENGR 122. The third course in the series, Data Technology, introduces students to $\mathrm{R}$ with an emphasis on data frames and data analysis. Content includes basic statistics, linear and nonlinear curve fitting, clustering, natural language processing, neural networks, databases, Structured Query Language (SQL), and data cleaning and management. The course instructor has developed a number of captioned videos covering topics such as $\mathrm{R}$ syntax and its difference from that of Python, functions, libraries, and databases. Students are asked to watch these videos and complete homework assignments before class, allowing them to learn and practice at their own pace prior to lecture. Example datasets used in the course include the 2012 Psychiatric admit database of 1.7 million records, the 2016 US Census data, baby name frequency from the Social Security Administration from 1880 to 2015, scraped content from live web pages, and current events news sources, the latter two of which are used to conduct sentiment analysis.

ENGR 195E. The final course in the series is a capstone project in which students apply computing skills acquired in the minor to solving problems or generating insights in their chosen area of study. Students work in self-selected teams and define their own project topics, typically pertaining to experimental data collection and analysis (common for, e.g., Psychology or Sociology majors) or cleaning and analysis of large, existing data sets (common for, e.g., Economics or Business majors). Specific examples include examining the relationship between technology literacy and aptitude for cybersecurity, and deduplicating 14.8M Amazon product reviews. Student teams submit their code, write a final paper, and give a presentation documenting their process and results.

\section{DEGREE PROGRAM EVOLUTION}

The first course in the minor, ENGR 120, was rolled out in Fall 2016, with additional courses introduced each semester thereafter until all four courses were in regular rotation. The minor has since evolved in response to feedback from students, faculty teaching the courses, faculty participating in the Interdisciplinary Computing Summer Institute, and industry partners. Below we highlight a few such changes. 
For the 2016-2017 academic year, ENGR 120 was taught by engineering faculty with a background in both computing and engineering education. From Fall 2017 onwards, however, this course has been taught by social science faculty with backgrounds in computing as well as psychology or economics. This choice was motivated by the following: (a) social science faculty are well-equipped to tailor course content to their students' interests; (b) they are familiar with and easily able to adjust for social science students' less extensive mathematics background relative to Engineering students; and (c) based on an informal survey of social science students, they feel less intimidated by faculty from their own departments.

To further enhance a sense of belongingness, ENGR 120 instructors now ask students to fill out a pre-course survey indicating their programming experience, motivation for enrolling in the course, and anxieties regarding the course. Averaged across several semesters, the vast majority of students (88\%) report having zero or very little programming experience. In turn, they report that their inexperience drives fears that they will fall behind and not be able to keep up with their peers. To attenuate these concerns, instructors provide a summary of these responses on the first day of class.

Regarding the tools employed in our courses, Python was initially taught via the Integrated Learning and Development Environment (IDLE). However, we later adopted Jupyter Notebook given its popularity for data analysis in both academia and industry, as well as its utility as an interactive teaching tool that has seen success at other universities (e.g., UC Berkeley's Data Science program). For courses using R, both RStudio and Jupyter Notebook are used.

Finally, a challenge that we continue to face is how to best provide students with real-world industry experience prior to graduating (i.e., internships). One key solution has been to invite industry partners to our Interdisciplinary Computing Summer Institute who specifically hire individuals with interdisciplinary computing backgrounds. These interactions have allowed us to foster relationships with local tech companies and better understand the skills they value when hiring employees for relevant entry-level positions. Furthermore, we have worked closely with staff at our university's Career Center, who recently created an online Canvas course entitled "Careers in Tech for Non-Tech Majors" that provides information on obtaining internships as well as finding mentors.

\section{APPLIED COMPUTING STUDENTS}

Here, we describe our approach for recruiting social science students into the Applied Computing minor, as well as demographic data for students in the first and final courses in the minor.

\subsection{STUDENT RECRUITMENT}

The Applied Computing minor is designed for students in the College of Social Sciences (e.g., Psychology, Economics) with interests in human behavior. As an initial step in developing recruitment materials, we informally surveyed Psychology majors and found that many students failed to see the relevance of computer programming to their interests. Many students believed that careers in tech necessitated technical degrees, and many voiced strong doubts as to whether tech companies value the social sciences. Students also worried that a lack of programming experience would put them at a disadvantage, causing them to struggle with difficult material taught by professors not experienced in teaching social science students, ultimately leading to poor grades.

To counter these beliefs, we developed recruitment materials that aim to (a) encourage students to diversify their skill set, enhance their marketability, and open new career pathways, (b) educate students about careers in interdisciplinary computing that value social science knowledge, (c) reassure them that the minor is built specifically for social science students with no prior programming experience, and (d) emphasize that course materials were carefully crafted to align with their interests, with the first course taught by social science faculty.

To advertise these messages, we maintain a website for the minor, post flyers in relevant departments, and hold information sessions during registration periods as well as transfer orientation sessions. During these sessions, we ask a current Applied Computing student to chat about their experience with the minor and emphasize that their own lack of programming experience did not impair their ability to succeed. We find that word-of-mouth passed down from current Applied Computing students is one of our most valuable and convincing recruiting tools. Additionally, given that faculty in Psychology and Economics have been closely involved in developing and teaching courses in the minor, they play a key role in generating enthusiasm not only among students, but among faculty in their departments, as well, who in turn encourage students to enroll in the minor.

Using the above approaches, we have had great success in recruiting students into Applied Computing courses. As demand for these courses has increased, we have begun offering the first three courses in both the spring and fall semester. Additionally, this fall, we added a second section of the first course to keep up with student demand.

\subsection{STUDENT PROFILE}

A profile of Applied Computing students can be found in Table 1, reflecting data from students enrolled in ENGR 120 (the first course in the minor) and ENGR 195E (the final course) for each academic year that the courses have been offered. Relative to other courses offered in the College of Engineering, Applied Computing students differ along several dimensions. Whereas only $19 \%$ of students enrolled in Engineering courses at our university are female, females now make up 67\% of ENGR 120 students, an increase from $47 \%$ when the course was first offered. Female representation is similarly higher in ENGR 195E (48\%) than in Engineering courses. In ENGR 120, the percentage of URM students-defined as African Americans, Hispanics, American Indians, Alaska Natives, Native Hawaiians, other Pacific Islanders, and individuals reporting more than one raceis now $47 \%$, up from $29 \%$ when the course was first offered, and 
TABLE 1: STUDENT PROFILE FOR THE FISRT COURSE (ENGR 120) AND FINAL COURSE (ENGR 195E)

\begin{tabular}{|c|c|c|c|c|c|}
\hline Demographic & Category & 120: $2016-2017$ & 120: $2017-2018$ & 120: 2018-2019 & 195: 2018, 2019 \\
\hline \# Students & & 42 & 76 & 70 & 31 \\
\hline \multirow[t]{2}{*}{ Gender } & Female & $47.6 \%$ & $57.9 \%$ & $67.1 \%$ & $48.4 \%$ \\
\hline & Male & $52.4 \%$ & $42.1 \%$ & $32.9 \%$ & $51.6 \%$ \\
\hline \multirow[t]{2}{*}{ Ethnicity } & URM & $28.6 \%$ & $38.2 \%$ & $47.1 \%$ & $29.0 \%$ \\
\hline & non-URM & $69.0 \%$ & $59.2 \%$ & $50.0 \%$ & $71.0 \%$ \\
\hline \multirow[t]{3}{*}{ Major } & Psychology & $50.0 \%$ & $51.3 \%$ & $38.6 \%$ & $32.3 \%$ \\
\hline & Economics & $28.6 \%$ & $19.7 \%$ & $17.1 \%$ & $29.0 \%$ \\
\hline & Other & $21.4 \%$ & $28.9 \%$ & $44.3 \%$ & $38.7 \%$ \\
\hline
\end{tabular}

Note: Some values may not sum to $100 \%$ given that students can decline to state gender/ethnicity. URM = underrepresented minority.

higher than the Engineering average (22\%) [16]. The percentage of URM students in ENGR 195E is $29 \%$, and we hope to see this number increase as our diverse students from ENGR 120 continue to move through the program.

With respect to student majors, the most popular major among Applied Computing students is Psychology, followed by Economics. Less common majors, collectively represented as Other in Table 1, include Sociology, Behavioral Science, Communication Studies, and Business. Among Applied Computing students, the majority have limited or no programming experience prior to taking the first course in the minor. On average, $62.9 \%$ report no programming experience, $25.1 \%$ report limited programming experience, and only $9.4 \%$ report moderate programming experience.

\section{ASSESSMENT}

Our assessment approach consists of two components: internal evaluation by our interdisciplinary faculty team and external evaluation by a nonprofit education research agency. As the Applied Computing program was being rolled out, formative assessment data served as an important feedback loop to enhance and optimize different elements of the program. With the recent graduation of our first full cohort of students, the data are being used to provide summative information about the ultimate outcomes of the program. We have used two main methods for data collection and review: (a) interviews: individual and group interviews with students, faculty and industry partners, and (b) surveys: administration of surveys to students, faculty and industry partners. With respect to student surveys, questions pertain to growth mindset [14], attitudes towards computer programming [3], and confidence in programming abilities. In the future, we plan to administer these same surveys to social science students not enrolled in Applied Computing courses to serve as a control group. Finally, our assessment protocol has employed an iterative process, such that we have tried a variety of different instruments to ascertain the usefulness of the data obtained from each, thereby allowing us to create a reduced set of the most useful questions and instruments.

\section{IMPACT}

The Applied Computing minor was launched in Fall 2016, with the first full cohort graduating in Spring 2019. Given that graduates are still job-hunting and analyses of the abovementioned assessment data are ongoing, here we briefly highlight a few preliminary findings with a focus on the final course in the series. As shown in Table 1, 48\% of ENGR 195E students were female and $29 \%$ were URMs, rates that are higher than those of classes in the College of Engineering, indicating that we have succeeded in broadening participation in computing education. We are optimistic that these numbers will further improve based on recent demographic data from the first course in the series (ENGR 120), given that many students from this class will continue forward with the minor.

Learning outcomes for the final course in the minor include representing social science data in appropriate classes and objects, as well as applying algorithms, packages, and data structures to social science problems. Students successfully demonstrated these outcomes by working in teams to use applied computing to solve a real-world social science problem (see section 3 for examples).

To assess students' own perceptions of the minor, we asked them to complete a voluntary survey querying them about their reasons for pursuing the minor, their attitudes towards computing, and their reaction to each of the four courses. Given that full datasets were collected from only 11 students, we are hesitant to draw conclusions from these data until additional survey results can be obtained from future graduates. Nonetheless, we provide a brief summary here.

Overall, survey respondents appeared satisfied with the Applied Computing minor and the skills and knowledge they acquired. As one respondent wrote, "Wonderful minor opportunity for those not in CS or Engineering! The staff and faculty behind this minor are amazing and really make the program special!" The majority of students felt their learning was supported very well by almost all aspects of Applied Computing courses, including working with peers, instructors and instructional student assistants, topics covered, final projects, and homework assignments. 
There was less agreement among students with respect to pacing of the courses, with some students indicating that the pace was too fast, and that the second course in the series, Data Structures and Algorithms, was quite difficult. Other students, however, indicated that the pace across courses was too slow. We speculate that students with existing programming knowledge may have found the pace too slow, whereas those with no background knowledge may have found the pace too fast - a hypothesis we plan to test further once we have a larger sample size.

When asked about their motivations for minoring in Applied Computing, students primarily mentioned wanting to be better prepared for the job market and wanting to improve their data analysis skills. When asked about the types of jobs they planned to pursue, all respondents mentioned a path that would make use of their interdisciplinary computing knowledge, including pursuing user experience research, data analytics, project management, and graduate programs in Cybersecurity or Neuroscience. Although we have only just begun tracking the career paths of these students, they have secured jobs that utilize their interdisciplinary computing skills at a variety of technology companies including Google, Piazza, Yahoo, and Facebook.

Finally, we asked students to provide suggestions for future Applied Computing students. Responses included: "Don't treat this course as if it were in the social sciences because you need to think in a different fashion"; "Work on projects that relate to work you want to do in the future"; "Be a proactive student, you won't be able to cram the concepts taught in class in one night. Don't be afraid to ask for help, coming to office hours really helped a lot."; "Don't be afraid of trying something new!" Taken together, students emphasized how different Applied Computing courses were from standard social science courses, but that nonetheless with an open mind and willingness to ask for help, one can succeed.

\section{CONCLUSIONS AND RECOMMENDATIONS}

Our interdisciplinary computing program presents an innovative approach to providing technology education to non-STEM students, thus making technology education more accessible to a broader segment of college students, including those who are traditionally underrepresented in Engineering or Computer Science. Moreover, our graduates' expertise in the social sciences coupled with their technical skills enables them to harness the power of information technology to advance possibilities across disciplinary boundaries, and to help address our nation's critical need for more technology-capable workers. Indeed, technology companies rely on employees with this unique combination of skills to gain insights about and improve upon products based on user-generated data. A recent report by the McKinsey Global Institute [10] estimates a demand for roughly 2-4 million such "business translators" in the next decade.

We hope to spur other campuses to develop similar programs by detailing our approach in developing an interdisciplinary computing minor degree. First, we wish to emphasize the importance of creating an interdisciplinary faculty team inclusive of those with backgrounds in social science,
CS/engineering, administration, and industry. This mix of perspectives enabled us to design and teach courses relevant to social science students' interests while maintaining an appropriate level of rigor necessary for the job market.

Second, we strongly recommend that recruitment efforts be targeted at students early enough in their college careers to complete a minor degree. Domain faculty tend to be the best drivers of student recruitment, given that they regularly interact with the target population and can assess their interests, developing recruitment materials accordingly.

Third, we encourage the development of new courses designed specifically for social science students, many of whom have a much less rigorous mathematical background than $\mathrm{CS} /$ engineering students. By reducing the technical prerequisites for taking such courses and adapting content to students' interests, these courses will be available to a wider, more diverse portion of the student population.

Finally, given that we are actively trying to improve in this area, we recommend that interested campuses establish industry partnerships early in the development process, ideally working with employers who can create internships for students, thereby providing invaluable career pathways for the next-generation technology-capable professionals.

\section{ACKNOWLEDGMENTS}

We wish to thank current and former members of our interdisciplinary faculty team. This project was supported in part by a US National Science Foundation Grant (DUE-1626600).

\section{REFERENCES}

[1] Burning Glass Technologies, The art of employment: How liberal arts graduates can improve their labor market practices. Boston, MA, 2013.

[2] Business-Higher Education Forum, Reskilling America's Workforce: Exploring the nation's future STEM workforce needs. National Science Foundation, Alexandria, VA, 2019.

[3] Brian Dorn and Allison E. Tew, "Empirical validation and application of the computing attitudes survey," Computer Science Education vol. 25, no. 1, pp. 136, 2015.

[4] Hermann Ebbinghaus, Memory: A contribution to Experimental Psychology. HA Ruger \& CE Bussenius, Tradutores, New York, NY, 1913.

[5] C. Goldin and L. F. Katz, The race between education and technology. Harvard University Press, Cambridge, MA, 2010.

[6] J. D. Karpicke and H. L. Roediger, "The critical importance of retrieval for learning," Science vol. 319, no. 5865, pp. 966-968, 2008.

[7] G. Kuh, High-impact educational practices: What they are, who has access to them, and why they matter. Association of American Colleges and Universities, Washington DC, 2008.

[8] V. Mayer-Schönberger and K. Cukier, Big data: A revolution that will transform how we live, work, and think. Houghton Mifflin Harcourt, New York, NY, 2013

[9] McKinsey Global Institute, Big data: the next frontier for innovation, competition and productivity. New York, NY, 2011.

[10] McKinsey Global Institute, The Age of Analytics: Competing in a Data-Driven World. New York, NY, 2016.

[11] National Center for Education Statistics. Table 318.20: Bachelor's, master's, and doctor's degrees conferred by postsecondary institutions, by field of study: Selected years, 1970/71 through 2016-17, 2018. Retrieved from: https://nces.ed.gov/programs/digest/d18/tables/dt18_318.20.asp

[12] National Science Board, Our nation's future competitiveness relies on building a STEM-capable US workforce. Alexandria, VA, 2018.

[13] President's Council of Advisors on Science and Technology, Engage to excel: Producing one million additional college graduates with degrees in science, technology, engineering, and mathematics. Washington, DC, 2012. 
[14] A. Rattan, K. Savani, D. Chugh, and C. Dweck, "Leveraging mindsets to promote academic achievement: Policy recommendations," Perspectives on Psychological Science vol. 10, no. 6, pp. 721-726, 2016.

[15] J. Rothwell, The hidden STEM economy. Washington D.C, 2013

[16] Institutional Effectiveness \& Analytics. 2019. Degrees Awarded by Degree Level: by College and Ethnicity. Retrieved from:

http://iea.sjsu.edu/Students/degrees/
[17] N. J. Slamecka and P. Graf, "The generation effect: Delineation of a phenomenon," fournal of Experimental Psychology: Human Learning and Memory vol. 4, no. 6, pp. 592-604, Nov. 1978.

[18] US Bureau of Labor Statistics, Projections of occupational employment, 2014-24. Career Outlook. Washington, DC, 2015. 